\title{
Effects of Cholinesterase Inhibiting Sage (Salvia officinalis) on Mood, Anxiety and Performance on a Psychological Stressor Battery
}

\author{
David O Kennedy*,', Sonia Pace', Crystal Haskell', Edward J Okello², Anthea Milne' and Andrew B Scholey' \\ 'Human Cognitive Neuroscience Unit, Division of Psychology, University of Northumbria, Newcastle upon Tyne, UK; and ${ }^{2}$ Medicinal Plant \\ Research Centre, University of Newcastle, Ridley Building, Newcastle upon Tyne, UK
}

\begin{abstract}
Salvia officinalis (sage) has previously been shown both to possess in vitro cholinesterase inhibiting properties, and to enhance mnemonic performance and improve mood in healthy young participants. In this double-blind, placebo-controlled, crossover study, 30 healthy participants attended the laboratory on three separate days, 7 days apart, receiving a different treatment in counterbalanced order on each occasion (placebo, 300, $600 \mathrm{mg}$ dried sage leaf). On each day mood was assessed predose and at I and $4 \mathrm{~h}$ postdose. Each mood assessment comprised completion of Bond-Lader mood scales and the State Trait Anxiety Inventory (STAl) before and after 20 min performance of the Defined Intensity Stress Simulator (DISS) computerized multitasking battery. In a concomitant investigation, an extract of the sage leaf exhibited dose-dependent, in vitro inhibition of acetylcholinesterase and, to a greater extent, butyrylcholinesterase. Both doses of sage led to improved ratings of mood in the absence of the stressor (that is, in pre-DISS mood scores) postdose, with the lower dose reducing anxiety and the higher dose increasing 'alertness', 'calmness' and 'contentedness' on the Bond-Lader mood scales. The reduced anxiety effect following the lower dose was, however, abolished by performing the DISS, with the same dose also being associated with a reduction of alertness during performance. Task performance on the DISS battery was improved for the higher dose at both postdose sessions, but reduced for the lower dose at the later testing session. The results confirm previous observations of the cholinesterase inhibiting properties of S. officinalis, and improved mood and cognitive performance following the administration of single doses to healthy young participants.
\end{abstract}

Neuropsychopharmacology (2006) 3 I, 845-852. doi:I0. I 038/sj.npp. I 300907; published online 5 October 2005

Keywords: anxiolytic; mood; stress; cognitive; Salvia officinalis; sage

\section{INTRODUCTION}

The history of the use of sage (several plants of the Salvia genus) as a medicinal treatment spans several millennia, and both ancient and modern cultures. Indications from the earliest texts onwards include its use as a treatment for the amelioration of age associated memory loss (Perry et al, 1999). A series of studies have shown that both Salvia lavandulaefolia (Spanish Sage) and Salvia officinalis (Garden Sage) do indeed possess properties potentially relevant to the attenuation of the cognitive decline associated with the downregulation of the cholinergic system seen in natural aging and dementia. Most pertinently, both have been shown to inhibit the cholinesterase

\footnotetext{
*Correspondence: Dr DO Kennedy, Human Cognitive Neuroscience Unit, Division of Psychology, University of Northumbria, Newcastle upon Tyne NEI 8ST, UK, Tel: + 44 191 20488|8, Fax: + 44 191 2274800, E-mail: david.kennedy@unn.ac.uk

Received 18 May 2005; revised 5 August 2005; accepted 15 August 2005

Online publication: 30 August 2005 at http://www.acnp.org/citations/ Npp083005050336/default.pdf
}

group of enzymes. Dose-dependent inhibition of butyrylcholinesterase (BuChE) by Salvia officinalis purpurea essential oil (Savelev et al, 2004) and inhibition of acetylcholinesterase (AChE) by both essential oils and extracts (Perry et al, 1996, 2000; Savelev et al, 2003) have been demonstrated in human postmortem brain tissue or bovine erythrocytes. Importantly, CNS availability has been confirmed with the observation that 5 days in vivo oral administration to rats of essential oil led to dose-dependent decreases in AChE activity in selected brain regions (Perry et al, 2002).

In keeping with these in vitro properties, the cognitive and mood effects of single doses of extracts with confirmed AChE-inhibiting properties have been assessed in placebocontrolled, randomised, balanced crossover studies in both young (Tildesley et al, 2003, 2005) and older ( $>65$ years) (Tildesley et al, submitted) human cohorts. In the case of the three such studies primarily assessing cognitive function, treatment with both encapsulated S. lavandulaefolia essential oil (Tildesley et al, 2003, 2005) and a dried ethanolic extract of S. officinalis (Tildesley et al, submitted), all of which treatments had AChE-inhibiting properties, led 
to improved memory performance on a computerized cognitive assessment battery. Additionally, attention task performance was improved in the older cohort (Tildesley et al, submitted), while self ratings of 'alertness', 'calmness' and 'contentedness' were improved in the young (Tildesley et al, 2005).

Previous research has shown that another plant species with cholinergic properties (Melissa officinalis; which has been shown to have the potential to bind to nicotinic and muscarinic receptors in human brain tissue) increased selfrated calmness in healthy young participants (Kennedy et al, 2002, 2003). Similarly, an ethanolic extract of $M$. officinalis significantly ameliorated the negative mood consequences of $20 \mathrm{~min}$ completion of a mild psychological stressor battery (DISS), again in healthy young humans (Kennedy et al, 2004).

The current double-blind, placebo-controlled study borrowed elements of the methodology of this last study, with an assessment of the anxiety and mood modulating properties of two separate single doses $(300$ and $600 \mathrm{mg}$, plus placebo, in counterbalanced order) of dried $S$. officinalis leaf in healthy young participants. Mood and anxiety were assessed both before and after $20 \mathrm{~min}$ completion of the DISS battery. Assessments took place predose and at 1 and $4 \mathrm{~h}$ postdose.

A concomitant in vitro investigation assessed the AChE and $\mathrm{BuChE}$ inhibiting properties of ethanolic extracts of the dried leaf.

\section{MATERIALS AND METHODS}

\section{Cholinesterase Assays}

Extract. Dried S. officinalis leaf (300 mg-MedicHerb, UK) was placed in a glass container with $3 \mathrm{ml}$ of $80 \%$ ethanol. The mixture was extracted ultrasonically for $10 \mathrm{~min}$ and the extract was decanted and filtered through Whatman No 41 filter paper into a clean flask. This same procedure was repeated a further two times. The solvent was evaporated using a rotary evaporator for $15 \mathrm{~min}$. The flask was weighed to determine dried weight of extract. The supernatant was reconstituted using 53\% ethanol and assayed using serial dilutions.
Assay. Acetylcholinesterase from human erythrocytes, acetylthiocholine iodide (ATChI), butyrylcholinesterase from human serum, butyrylthiocholine iodide (BTChI), 5:5-dithiobis-2-nitrobenzoic acid (DTNB) and sodium bicarbonate were purchased from Sigma Co., UK.

An assessment of cholinesterase inhibition was carried out on 96-well microtiter plates using a colorimetric method of Ellman et al (1961) A typical run consisted of $5 \mu$ l of human AChE or BuChE solution, at final assay concentrations of $0.03 \mathrm{U} / \mathrm{ml} ; 200 \mu \mathrm{l}$ of $0.1 \mathrm{M}$ phosphate buffer $\mathrm{pH} 8 ; 5 \mu \mathrm{l}$ of DTNB, at a final concentration of $0.3 \mathrm{mM}$ prepared in $0.1 \mathrm{M}$ phosphate buffer $\mathrm{pH} 7$ with $0.12 \mathrm{M}$ of sodium bicarbonate; and $5 \mu \mathrm{l}$ of the test extract reconstituted in $53 \%$ ethanol. The reactants were mixed in a 96-well microtitre plate and the mixture preincubated for $15 \mathrm{~min}$ at $30^{\circ} \mathrm{C}$. The reaction was initiated by adding $5 \mu \mathrm{l}$ of ATChI or BTChI at final concentrations of $0.5 \mathrm{mM}$. As a control, the extract solution was replaced with $53 \%$ ethanol. The control was assayed in triplicate. To monitor any nonenzymatic hydrolysis in the reaction mixture a blank consisting of buffer-replacing enzyme was run in triplicate. Change in absorbance at $405 \mathrm{~nm}$ was measured on a Thermo Labsystems Multiskan Ascent 96-well plate reader, equipped with Ascent Software, for a period of $10 \mathrm{~min}$ at $30^{\circ} \mathrm{C}$.

Cholinesterase properties. The S. officinalis extract exhibited dose-dependent ChE-inhibiting properties, but was a more selective inhibitor of BuChE than AChE (IC50 s of 0.054 and $0.365 \mathrm{mg} / \mathrm{ml}$, respectively). The data from the ChE inhibition assays is represented in Figure 1.

\section{Anxiety/Mood/Performance Assessment}

Participants. In all, 17 males and 13 females (mean age $=24.4$ years, $\mathrm{SD}=4.4$ ) took part in the study, which was approved by the Ethics Committee of the Psychology Division of Northumbria University and was carried out in accordance with the Declaration of Helsinki. Before taking part in the study, participants signed an informed consent form and completed a medical health questionnaire. All participants reported that they were in good health, were not taking any recreational or prescription drugs, with the
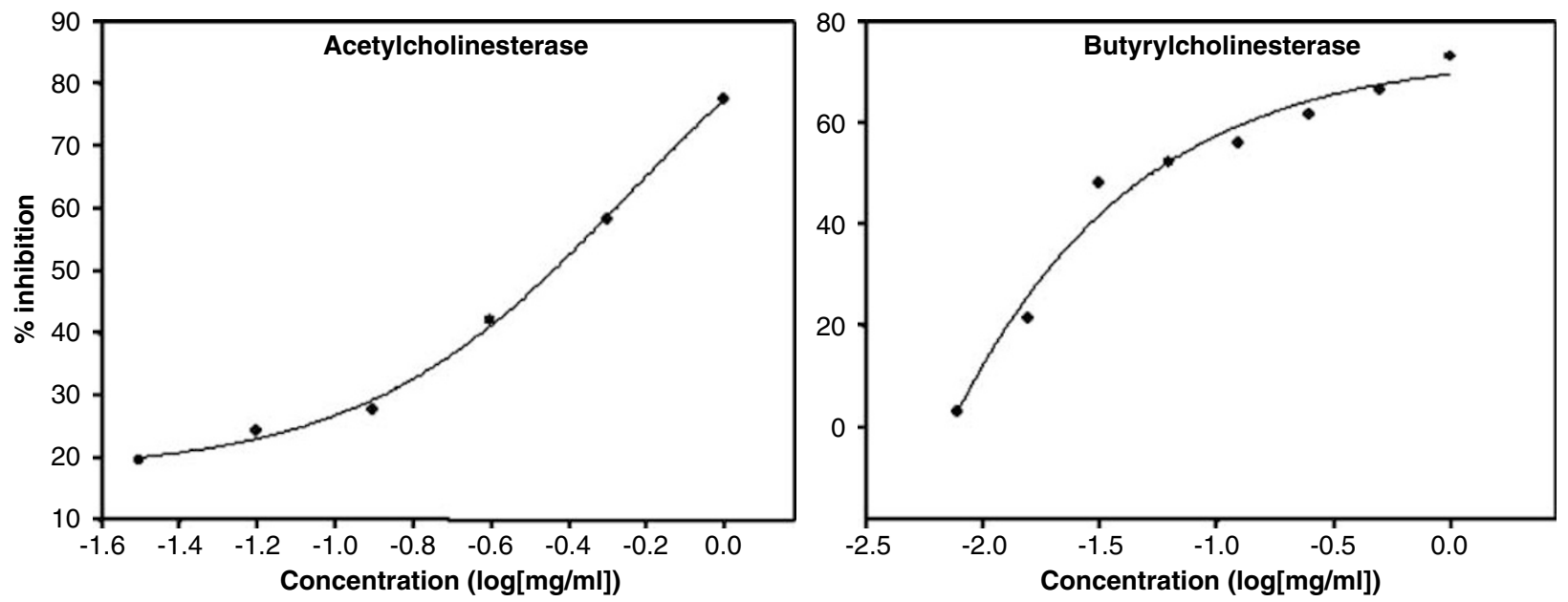

Figure I Inhibition of AChE and BuChE by the ethanolic extract of dried Salvia officinalis leaf. 
exception of oral contraceptive pills and were nonsmokers. Participants refrained from consuming any caffeine containing products for a minimum of $2 \mathrm{~h}$, and alcohol for a minimum of $12 \mathrm{~h}$ prior to each testing session.

Treatments. Dried leaf of S. officinalis (MedicHerb UK Ltd, Marlow, Buckinghamshire) and an inert placebo were encapsulated in identical opaque capsules for the study. Treatments were counterbalanced in an order dictated by random allocation of the participant to a Latin square. All individual participants' daily treatments were coded and prepackaged in identical containers by a disinterested third party prior to commencement of the study.

On each study day participants received four capsules of identical appearance, each containing either placebo or $150 \mathrm{mg}$ of S. officinalis dried leaf. Depending on the condition to which they were allocated on that particular day the combination corresponded to a dose of either $0 \mathrm{mg}$ (placebo), 300 , or $600 \mathrm{mg}$ of S. officinalis dried leaf. Following completion of each testing session participants were asked whether they had formed any opinion as to the nature of the day's treatment.

\section{Materials}

The Defined Intensity Stressor Simulation (DISS) computerized battery. The DISS-computerized battery (www. stress-sim.co.uk) comprises a set of four concurrent cognitive and psychomotor tasks presented via a split screen. All responses are made with an external mouse. In this instance a $20 \mathrm{~min}$ version of the DISS was employed. The modules selected were the 'mathematical processing', 'Stroop Color-Word', 'High Number Tap' and 'memory search' tasks. Participants are instructed via on screen standard instructions to attend simultaneously to all four tasks, while monitoring the central counter displaying their accumulated aggregate score. Accuracy and speed of response dictate the score, with failure to respond resulting in negative scoring. Previous research has shown that the DISS engenders increases in self-ratings of negative mood, arousal and stress-related physiological responses (Wetherell and Sidgreaves, 2005; Kennedy et al, 2004).

In the current study, the 'stroop color-word' and 'highest number tap' tasks were set at a high difficulty/intensity level and the 'mathematical processing' and 'memory search' tasks were set at a medium difficulty/intensity level. The battery was performed for $20 \mathrm{~min}$. The on screen layout of the battery is shown in Figures 1 and 2. The four tasks are described below.

Mathematical processing: A series of calculations are presented. The participant adds two numbers, entering the three figure answer via an onscreen number pad. On completion of each calculation, the participant clicks on the 'done' button which cues the next calculation. Ten points are awarded for each correct answer and ten points deducted from the running total for each incorrect answer.

Stroop color-word: Words describing one of four colors ('RED', 'YELLOW', 'GREEN', 'BLUE') are presented in different colored fonts on the left of the module area. The participant clicks on color panels on the right of the module

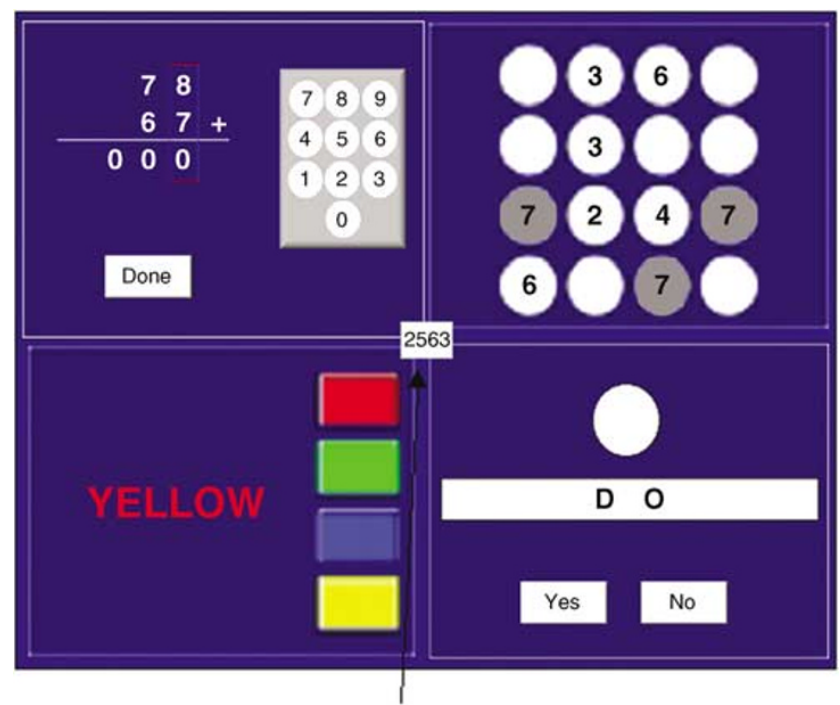

Figure 2 On screen layout of the Defined Intensity Stress Simulator battery showing (from top left clockwise) the 'Mathematical processing', 'Highest Number Tap', 'Memory search' and 'Stroop Color-Word' tasks. Individual scores are generated for each module, with a running total score in the centre of the display.

area in order to identify the font color (eg if the word 'GREEN' is presented in a blue font, the correct response would be to click on the blue panel). A total of 10 points are awarded for every correctly identified color, with 10 points deducted for each incorrect answer, or for not responding in the allotted time.

Highest number tap: A grid containing digits between 0 and 9 appear. The participant identifies the numerically highest digit and then clicks on all of the instances of the digit presented on the screen in order to activate them. Once all instances of the highest digit have been successfully activated the grid is replaced. A total of 10 points are awarded for each grid cleared, with 10 points deducted for any grids not fully activated within the time limit.

Memory search: Four letters appear for the participants to remember. After $4 \mathrm{~s}$ the letters disappear but can be viewed again by clicking on 'retrieve list' button. Approximately every $10 \mathrm{~s}$ a single target letter appears. Participants are instructed to indicate whether the target letter had appeared in the original list of four letters by clicking on the 'yes' or 'no' buttons. A total of 10 points are awarded for a correct answer, 10 points deducted for an incorrect answer or no response, and five points are deducted every time the list is retrieved.

\section{Mood Measures}

Mood was assessed both before and after each completion of the DISS battery utilizing the State-Trait Anxiety Inventory (STAI) (Speilberger et al, 1969) and Bond-Lader visual analogue mood scales (Bond and Lader, 1974).

STAI (Speilberger et al, 1969). The STAI 'State' subscale is a widely used instrument for measuring fluctuating levels of anxiety. The subscale contains 20 statements (eg 'I am 
calm') each with a 4-point Likert scale. Participants rate how much they feel like each statement at the time of making the response. Scores on the STAI range from 20 to 80 , with higher scores representing higher levels of anxiety.

Bond-Lader visual analogue mood scales (Bond and Lader, 1974). These scales were originally designed for assessing the mood effects of anxiolytics and have been subsequently utilized in numerous pharmacological, psychopharmacological and medical trials. As with other mood visual analogue scales high reliability and validity have been demonstrated (Ahearn, 1997).

The Bond and Lader scales comprise a total of sixteen $100 \mathrm{~mm}$ lines anchored at either end by antonyms (eg alertdrowsy, calm-excited). Participants mark their current subjective position between the antonyms on the line. Each line is scored as millimeters to the mark from the negative antonym. From the resultant scores three measures derived by factor analysis can be isolated (Bond and Lader, 1974): 'alertness', 'calmness' and 'contentedness'. Scores for each factor represent the average number of millimeters ( $\max$ $100 \mathrm{~mm}$ ) from the individual scales contributing to the factor.

Data from the pre- and post-DISS mood measures was used in three separate analyses (see 'data for analysis' below).

\section{Procedure}

Prior to the first study day participants were randomly allocated to a treatment regime dictated by a Latin square, which counterbalanced the order of treatments across the 3 days of the study. Each of the 3 days was separated by a 7day 'wash-out' period, with testing taking place, commencing at 09:00, in dedicated laboratory facilities.

Immediately prior to and following each completion of the DISS battery participants filled out the STAI state subscale and Bond-Lader mood scales.

Each day of the study comprised an initial predose completion of the 20-min DISS battery (plus mood scales before and after), followed by ingestion of the day's treatment. At 1 and $4 \mathrm{~h}$ postdose, participants completed the DISS battery again (plus mood scales before and after).

\section{Statistics}

Data for analysis. Mood effects in the absence of the stressor: In order to establish the mood effects of the treatments in the absence of the stressor, change from predose baseline, in mood scores assessed before undertaking the DISS battery (ie the pre-DISS score) were calculated at the 1 and $4 \mathrm{~h}$ postdose sessions.

Mood effects during the DISS: In order to establish the effects of the treatments on the stress related change in STAI and Bond-Lader mood scores inculcated by the DISS battery, a 'change during DISS' score was calculated at each session (post DISS mood score minus pre-DISS mood score). Change from baseline scores at 1 and $4 \mathrm{~h}$ postdose were then calculated by subtracting the predose 'change during DISS' score from the postdose 'change during DISS' scores ( 1 and $4 \mathrm{~h})$.
DISS performance effects: In order to establish treatment related effects in task performance, change from predose baseline scores on the DISS were calculated at the 1 and $3 \mathrm{~h}$ postdose sessions.

\section{Analysis}

For all measures (see above), prior to carrying out planned comparisons, an ANOVA (General Linear Model), with terms fitted to the model for dose (placebo, 300 and $600 \mathrm{mg}$ ), session ( 1 and $4 \mathrm{~h}$ ), dose $\times$ session and participant was carried out to identify main effects and interaction effects on change from baseline data for each measure.

The primary statistical analysis of the 'change from baseline' data for each measure was undertaken using planned comparisons, utilizing $t$-tests with the MSError from an omnibus ANOVA as an error term (Keppel, 1991). For each measure, change from baseline data from the placebo condition were compared to that for the two active doses $(300$ and $600 \mathrm{mg})$ at the two postdose testing sessions. To ensure the overall Type I error protection level only those planned comparisons associated with measures that generated a significant main effect or interaction effect on the initial ANOVA (statistic not reported) are reported. Furthermore, all testing was two-tailed, comparisons were strictly planned prior to the study, were restricted to the number of conditions minus one at each timepoint, and only probabilities associated with these preplanned comparisons were calculated.

\section{RESULTS}

\section{Mood Effects of DISS}

Prior to the primary analysis of mood and performance data (planned comparisons - see above) a 3-way repeated measures ANOVA (pre/post DISS mood scores $\times$ pre-treatment/ posttreatment $\times$ condition) was carried out utilizing raw STAI and Bond-Lader mood scores to establish the overall effects of the DISS battery on mood.

This analysis showed that there was a significant main effect $(\mathrm{F}(1,29)=6.67, p=0.015)$ of DISS completion on the state subscale of the STAI, with anxiety ratings rising from 33.1 to 34.6 during DISS completion.

There was also a significant main effect $(\mathrm{F}(1,29)=6, p=$ 0.021 ) of DISS completion on 'alert' scores from the BondLader visual analogue scales with scores decreasing from 69 (average millimeters) pre-DISS to $66 \mathrm{~mm}$ post-DISS. Similarly 'content' was significantly reduced $(\mathrm{F}(1,29)=4.28$, $p=0.048$ ) with average ratings reducing from 70.7 to $69.1 \mathrm{~mm}$.

Mean data for the Pre-DISS mood scores, change in score during DISS and the data utilized for the following analyses is presented in Table 1 .

\section{Mood Effects in the Absence of the Stressor}

Planned comparisons of the pre-DISS mood scores (change from predose baseline) showed that both doses of sage had a significant effect on ratings of mood in the absence of the stressor in comparison to placebo. In the case of the lower dose $(300 \mathrm{mg})$, 'state anxiety' was significantly reduced at 


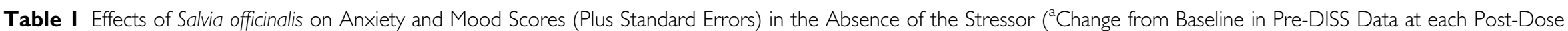

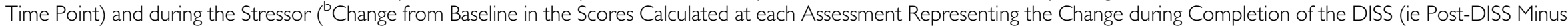
Pre-DISS at each Time Point))

\begin{tabular}{|c|c|c|c|c|c|c|c|c|c|c|c|c|c|c|c|c|c|c|}
\hline & \multicolumn{4}{|c|}{ Predose DISS } & \multicolumn{7}{|c|}{ I h postdose DISS } & \multicolumn{7}{|c|}{$4 \mathrm{~h}$ postdose DISS } \\
\hline & \multicolumn{2}{|c|}{$\begin{array}{l}\text { Pre-DISS } \\
\text { score }\end{array}$} & \multicolumn{2}{|c|}{$\begin{array}{l}\text { Change in score } \\
\text { during DISS }\end{array}$} & $\begin{array}{l}\text { Pre-DISS } \\
\text { score }\end{array}$ & \multicolumn{2}{|c|}{$\begin{array}{l}\text { Change in score } \\
\text { during DISS }\end{array}$} & \multicolumn{2}{|c|}{$\begin{array}{c}{ }^{\text {a }} \text { Change in Pre-DISS } \\
\text { scores }\end{array}$} & \multicolumn{2}{|c|}{$\begin{array}{l}\text { bChange in change } \\
\text { during DISS scores }\end{array}$} & $\begin{array}{l}\text { Pre-DISS } \\
\text { score }\end{array}$ & \multicolumn{2}{|c|}{$\begin{array}{l}\text { Change in score } \\
\text { during DISS }\end{array}$} & \multicolumn{2}{|c|}{ 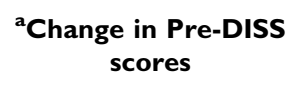 } & \multicolumn{2}{|c|}{$\begin{array}{l}{ }^{b} \text { Change in change } \\
\text { during DISS scores }\end{array}$} \\
\hline \multicolumn{19}{|l|}{ State } \\
\hline Placebo & 33.00 & 1.48 & 2.57 & 1.04 & $33.07 \quad 1.59$ & 1.33 & 0.86 & 0.07 & 0.82 & -1.23 & 1.00 & $\begin{array}{lll}33.07 & 1.59\end{array}$ & 1.93 & 0.95 & 0.13 & 0.88 & -0.63 & 1.06 \\
\hline $300 \mathrm{mg}$ & 34.50 & 1.91 & -0.57 & 0.88 & $32.70 \quad 1.99$ & 2.57 & 0.68 & -1.80 & 0.81 & 3.13 & 1.00 & $32.70 \quad 1.99$ & 2.00 & 0.82 & -2.37 & 0.79 & 2.57 & 1.14 \\
\hline $600 \mathrm{mg}$ & 33.87 & 1.68 & 1.63 & 1.15 & $33.07 \quad 1.41$ & 0.50 & 0.92 & -0.80 & 1.12 & -1.13 & 0.99 & $33.07 \quad|.4|$ & 0.97 & 0.97 & -1.07 & 1.30 & -0.67 & 1.27 \\
\hline \multicolumn{19}{|l|}{ Alert } \\
\hline Placebo & 68.70 & 3.31 & -3.82 & 1.89 & 65.893 .38 & 0.36 & 1.70 & -2.81 & 2.50 & 4.18 & 2.62 & 67.543 .00 & -1.02 & 2.34 & -1.16 & 2.84 & 2.80 & 3.04 \\
\hline $300 \mathrm{mg}$ & 68.09 & 3.82 & -0.96 & 1.76 & $70.30 \quad 3.67$ & -6.60 & 2.57 & 2.21 & 1.27 & -5.64 & 1.91 & $70.38 \quad 4.04$ & -6.35 & 3.82 & 2.29 & 1.95 & -5.39 & 3.51 \\
\hline $600 \mathrm{mg}$ & 66.91 & 3.68 & -1.38 & 2.63 & $71.59 \quad 3.29$ & -4.43 & 2.04 & 4.68 & 2.66 & -3.04 & 3.50 & $70.82 \quad 3.35$ & -1.90 & 1.93 & 3.91 & 2.12 & -0.52 & 3.36 \\
\hline \multicolumn{19}{|l|}{ Content } \\
\hline Placebo & 72.29 & 3.08 & -3.34 & 1.78 & $70.52 \quad 3.50$ & 0.05 & 1.37 & -1.77 & 1.40 & 3.39 & 2.22 & $71.21 \quad 3.29$ & -1.54 & 1.98 & -1.08 & 1.80 & 1.80 & 2.57 \\
\hline $300 \mathrm{mg}$ & 70.19 & 3.50 & -2.47 & 1.35 & $69.41 \quad 3.81$ & -2.45 & 1.34 & -0.77 & 1.19 & 0.02 & 1.71 & $69.35 \quad 3.99$ & -1.25 & 2.45 & -0.83 & 1.53 & 1.22 & 2.36 \\
\hline $600 \mathrm{mg}$ & 68.41 & 3.72 & 0.40 & 1.80 & $71.41 \quad 3.27$ & -0.57 & 1.30 & 2.99 & 2.36 & -0.97 & 2.57 & $72.95 \quad 2.73$ & -2.09 & 1.98 & 4.54 & 2.44 & -2.49 & 2.47 \\
\hline \multicolumn{19}{|l|}{ Calm } \\
\hline Placebo & 72.23 & 4.03 & -7.88 & 3.53 & $68.03 \quad 4.20$ & -2.75 & 2.34 & -4.20 & 3.53 & 5.13 & 4.13 & $61.98 \quad 3.74$ & -0.45 & 2.74 & -10.25 & 3.71 & 7.43 & 4.02 \\
\hline $300 \mathrm{mg}$ & 68.82 & 3.89 & -4.32 & 3.52 & $65.95 \quad 4.03$ & -4.35 & 3.61 & -2.87 & 3.09 & -0.03 & 3.73 & $67.10 \quad 4.12$ & -1.08 & 4.43 & -1.72 & 1.68 & 3.23 & 3.47 \\
\hline $600 \mathrm{mg}$ & 66.18 & 3.62 & -8.83 & 4.17 & $65.18 \quad 4.02$ & -2.30 & 4.13 & -1.00 & 3.85 & 6.53 & 4.60 & $68.63 \quad 3.50$ & -4.12 & 4.36 & 2.45 & 4.17 & 4.72 & 4.17 \\
\hline
\end{tabular}

aData used for 'mood effects in the absence of the stressor' analysis.

'Data used for 'effects of treatment on mood change during the DISS' analysis. 
both the $1 \mathrm{~h}(\mathrm{t}(58)=2.11, p=0.04)$ and $4 \mathrm{~h}(\mathrm{t}(58)=2.83$, $p=0.006$ ) time points, while 'alertness' was increased at the $1 \mathrm{~h}$ time point $(\mathrm{t}(58)=2.05, p=0.044)$, and 'calmness' at the $4 \mathrm{~h}(\mathrm{t}(58)=2.63, p=0.011)$ time point. Following the higher dose $(600 \mathrm{mg})$ ratings on all three Bond-Lader factors were improved, with increased 'alertness' at both $1 \mathrm{~h}$ $(\mathrm{t}(58)=3.06, p=0.003)$ and $4 \mathrm{~h}(\mathrm{t}(58)=2.07, p=0.047)$ postdose, increased 'contentedness' at $1 \mathrm{~h}(\mathrm{t}(58)=2.8$, $p=0.007)$ and $4 \mathrm{~h}(\mathrm{t}(58)=3.3, p=0.002)$, and increased 'calmness' at $4 \mathrm{~h}(\mathrm{t}(58)=3.9, p<0.001)$ postdose. The mood effects of $S$. officinalis in the absence of the stressor are represented graphically in Figure 3a.

\section{Effects of Treatment on Mood Change during the DISS}

Both Sage treatments led to modulation of the stressinducing effects of the DISS battery. This effect was most pronounced for the $300 \mathrm{mg}$ dose, with both increased anxiety and decreased alertness during the battery at $1 \mathrm{~h}$ (anxiety $\quad(\mathrm{t}(58)=3.9, \quad p<0.001)$, alertness $\quad(\mathrm{t}(58)=3.24$, $p=0.002)$ and $4 \mathrm{~h}$ (anxiety $(\mathrm{t}(58)=2.86, p=0.006$ ), alertness $(\mathrm{t}(58)=2.7, p=0.009))$ postdose. The $600 \mathrm{mg}$ dose led to a single significant effect, with the change in alertness being reduced at the $1 \mathrm{~h}$ time point $(\mathrm{t}(58)=2.4, p=0.02)$. The mood effects of $S$. officinalis during the stressor are represented graphically in Figure $3 \mathrm{~b}$.

\section{Effects of Treatment on Performance of the DISS Battery}

Both doses led to modulation of performance on the DISS battery. In the case of the lower dose this modulation took the form of significant decrements on the 'Highest Number Tap' module score at both postdose time points $(1 \mathrm{~h}$ $(\mathrm{t}(58)=3.25, p=0.002), 4 \mathrm{~h}(\mathrm{t}(58)=4.07, p<0.001))$ and on the aggregate DISS battery score at $4 \mathrm{~h}$ postdose $(\mathrm{t}(58)=3.65, p=0.001)$.

In contrast the higher dose was associated with improved performance on the 'Stroop' module at both postdose time points $(1 \mathrm{~h}(\mathrm{t}(58)=5.05, p<0.001), 4 \mathrm{~h}(\mathrm{t}(58)=5.67$, $p<0.001)$ ). Similarly, the aggregate score for the battery was significantly raised at both time points $(1 \mathrm{~h}(\mathrm{t}(58)=3.65$, $p=0.001), 4 \mathrm{~h} \quad(\mathrm{t}(58)=4.1, p<0.001))$. The effects of $S$. officinalis on task performance are represented graphically in Figures $3 c$ and 4.

\section{DISCUSSION}

The results of the current study confirm that acute administration of $S$. officinalis can beneficially modulate mood in healthy young participants. In the case of the lower
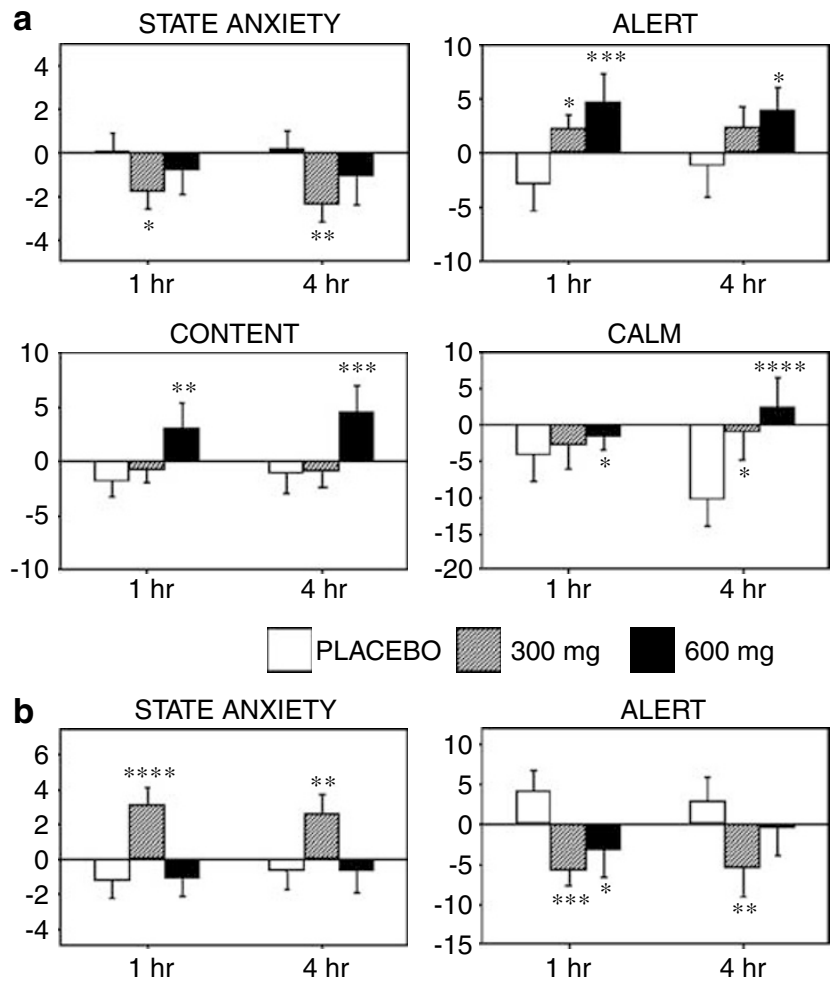

Figure 3 The effects of Salvia officinalis on anxiety and mood (a) in the absence of the stressor (data from footnote ' $a$ ' in Table I) and (b) during the stressor (data data from footnote ' $b$ ' in Table I). Data is change from baseline $(* p<0.05, * * * 0.01$, $* * * * 0.005$, ***** $p<0.00$ I from planned comparisons).

\begin{tabular}{ll|rr|rrrr}
\hline & & \multicolumn{2}{|c|}{$\begin{array}{c}\text { Pre-dose } \\
\text { Score }\end{array}$} & \multicolumn{4}{c}{ Change from Baseline } \\
& & 1 hour post-dose & 4 hours post-dose \\
\hline Mathemetical & placebo & 626.55 & 43.04 & 30.00 & 21.76 & 54.83 & 21.49 \\
processing & $600 \mathrm{mg}$ & 667.59 & 54.23 & 65.52 & 25.50 & 82.07 & 24.03 \\
& 645.17 & 48.91 & 27.93 & 18.19 & 91.38 & 28.90 \\
Highest & placebo & 1949.66 & 154.2 & 184.14 & 52.86 & 307.59 & 54.10 \\
NumberTap & $300 \mathrm{mg}$ & 2104.14 & 161.7 & -1.38 & 54.66 & 74.83 & 73.35 \\
& $600 \mathrm{mg}$ & 1799.66 & 141.0 & 221.03 & 45.46 & 301.38 & 77.52 \\
Memory & placebo & 685.69 & 13.31 & -4.83 & 14.45 & 10.86 & 15.48 \\
search & $300 \mathrm{mg}$ & 703.45 & 17.76 & -5.69 & 19.13 & -12.76 & 20.90 \\
& $600 \mathrm{mg}$ & 662.41 & 26.96 & -0.86 & 22.26 & 24.48 & 27.15 \\
Stroop & placebo & 1568.97 & 81.30 & 0.34 & 35.42 & 94.48 & 40.50 \\
Colour-Word & $300 \mathrm{mg}$ & 1539.31 & 92.04 & 60.34 & 52.55 & 60.34 & 65.18 \\
& $600 \mathrm{mg}$ & 1244.14 & 175.8 & 225.86 & 120.70 & 347.93 & 147.39 \\
Total Score & placebo & 4830.17 & 189.6 & 210.00 & 56.27 & 468.10 & 59.55 \\
& $300 \mathrm{mg}$ & 5013.79 & 226.6 & 118.45 & 95.76 & 204.14 & 108.52 \\
& $600 \mathrm{mg}$ & 4351.72 & 310.6 & 473.62 & 153.05 & 764.83 & 195.73
\end{tabular}
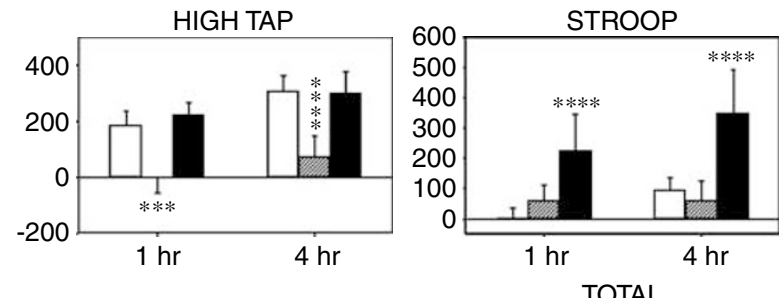

PLACEBO

$300 \mathrm{mg}$

$600 \mathrm{mg}$

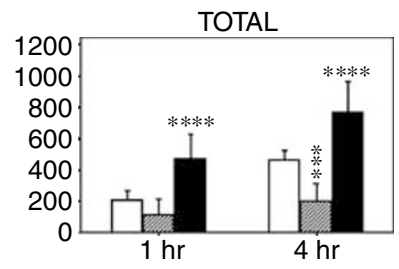

Figure 4 The effects of Salvia officinalis on performance scores (plus standard errors) on individual modules and the total score for the DISS battery. Graphs represent the measures that evinced a significant effect on the initial ANOVA (*** $p<0.005, * * * * p<0.00$ I from planned comparisons). 
dose of sage $(300 \mathrm{mg})$ these improvements were seen in terms both of pre-DISS scores on the STAI state anxietysubscale at both postdose testing sessions, and increased 'alertness' at the $1 \mathrm{~h}$ session and increased calmness at the $4 \mathrm{~h}$ testing session (both of the latter on the Bond-Lader scales). While the higher dose had no significant effect on the STAI, it did result in improved scores on all three BondLader factors ('alertness', 'contentedness', 'calmness') at both postdose time points (with the exception of 'calmness' at $1 \mathrm{~h}$ ). These improved subjective mood scores on the Bond-Lader scales directly replicate the improved scores previously seen on the same instrument following $50 \mu \mathrm{l}$ of an AChE-inhibiting sage essential oil (Tildesley et al, 2005).

The modulation of mood during the DISS battery (ie the change in scores from pre- to post-DISS mood assessment) associated with $S$. officinalis is less clearcut. The lower dose was associated with increased anxiety and decreased 'alertness'. Given that the same dose evinced reduced anxiety and increased 'alertness' in the pre-DISS scores this pattern of changes during DISS performance may simply represent an attenuation by the stressor of general treatment-associated mood gains.

The lower dose was also associated with significant decrements on the High Tap module (at 1 and $4 \mathrm{~h}$ ) and the overall DISS battery scores (at $4 \mathrm{~h}$ ). In sharp contrast the higher dose resulted in improved performance on the Stroop module and on the DISS battery aggregate score at both time points.

This somewhat contrasting pattern of results across the mood and performance measures suggests that the lower dose falls somewhere below the treatment threshold required to beneficially modulate mood and performance. The distinction between the reduction of anxiety for the lower dose, and the improvement in general mood for the higher dose in the absence of the stressor may be particularly telling, and may suggest that the psychopharmacological effects of the two doses are somewhat different, either in terms of mechanisms activated (given that a number of separate dose-dependent mechanisms may be involved), or simple degree. Certainly the general anxiolytic effect of the lower dose, either in terms of mechanisms or subjective experience, may have contributed to the performance decrements, and it remains a possibility that the negative shift in mood then seen during the DISS performance was inculcated by the participants' subjective experience of impaired performance. The somewhat complicated pattern of the data within and across doses may also be due simply to the complex mixture of potential, pharmacologically active constituents within the leaves. While previous research (see Kennedy and Scholey, 2005) suggests that the cholinesterase inhibiting properties of the major constituents are as a result of a synergistic relationship, it would be of great interest to investigate the direct behavioral effects of whole extracts versus single constituents.

Interestingly, where the current results suggest that the lower dose employed is below, and the higher dose is within, the beneficial therapeutic window for this specific dried leaf, the previous research using essential oil and ethanolic extracts (Tildesley et al, 2003, 2005; Tildesley et al, submitted) showed the opposite dose-response relationship, with the lower doses that were employed proving more effective. This same pattern of differential dose-response relationships for concentrated extracts (negative doseresponse) and dry leaf (positive dose-response), respectively, has also been seen previously with $M$. officinalis (Kennedy et al, 2002, 2003). These findings highlight, in particular, our current lack of understanding of the mechanistic and behavioral consequences of differing extraction techniques.

With regards the specific mechanisms driving the mood and performance effects seen here, it is certainly a possibility that the exhibited $\mathrm{AChE}$ and BuChE inhibitory properties may be wholly or partly responsible. We currently have no information on the relationship between the in vitro cholinesterase inhibiting properties of $S$. officinalis, as demonstrated here, and any in vivo inhibition in humans. However, it is interesting to make a comparison with the two studies that demonstrated an improvement in mnemonic performance (Tildesley et al, 2003, 2005). In these previous studies the essential oil exhibited an IC50 of approximately $0.07 \mathrm{mg} / \mathrm{ml}$ (BuChE was not investigated), whereas in the current case the extract was a more selective inhibitor of BuChE (IC50 of $0.054 \mathrm{mg} / \mathrm{ml}$ ) than AChE (IC50 of $0.365 \mathrm{mg} / \mathrm{ml}$ ). Again, the direct relevance of these similarities/differences requires further investigation.

It is also entirely possible that as yet undelineated properties underlie either the mood or cognitive effects seen here. As an example, while extracts of $M$. officinalis (also a member of the Labiatae family) have been shown to bind directly to both muscarinic and nicotinic receptors in human brain tissue (eg Kennedy et al, 2003), potential receptor-binding properties (in any neurotransmitter system) have not, as yet, been investigated in extracts of $S$. officinalis. It therefore seems premature to attribute any effects to a specific mechanism simply on the basis that it has been demonstrated. Indeed the differential pattern of results for the two doses of $S$. officinalis under investigation suggest the possibility that they may represent the action of different psychopharmacological mechanisms.

While the current study utilized a sample of healthy young adults, who we can assume are near, or at, their peak in terms of brain function, the utility of sage as a cognition/ mood enhancer may well lie in the direction of dementias such as Alzheimer's disease (AD), and age-associated cognitive decline. Both of these may be, in part, a consequence of downregulation of the cholinergic system. Current treatments for $\mathrm{AD}$ almost exclusively consist of drugs that inhibit both ChE types, or more commonly AChE alone. In both cases this leads to an augmentation in the availability of the neurotransmitter acetylcholine. They are attributed with a 'significant, although modest, effect on the cognitive status of patients with AD' (Grutzlender and Morris, 2001), and include the plant- (snowdrop and daffodil bulb) derived drug galantamine (Wilcock et al, 2000). However, these alkaloid drugs can be toxic, offering a narrow therapeutic window, and are often associated with a number of deleterious side effects. The Salvia species $S$. officinalis and S. lavandulaefolia are both edible, not toxic (at any of the doses that are liable to be utilized in humans) and have long histories of safe usage. Of particular interest here, it has been demonstrated that while AChE levels are significantly reduced in $\mathrm{AD}$ (in comparison to healthy brains), BuChE levels are liable to be increased (Giacobini, 
2004). This suggests that treatments that predominantly inhibit BuChE (as here) may prove particularly efficacious in the augmentation of ACh levels. Added to this, the mood improvements seen here and elsewhere in humans, and other key properties that may slow the pathogenesis of disease or natural decline (eg antioxidant, anti-inflammatory, oestrogenic (Perry et al, 2001, 2003)), suggest that sage may well confer a number of benefits above and beyond current treatments. Preliminary support for this is provided by the two studies that have assessed the effects of sage species in $\mathrm{AD}$. In the first, preliminary, open-label, pilot study, Perry et al (2003) assessed the tolerability of 6 weeks oral administration of an AChE inhibitory S. lavandulaefolia essential oil in 11 patients. Although the trial did not include a placebo condition the results were promising, with excellent tolerability of the extract, and suggestive significant improvements at the 6 week end- point seen on both the accuracy of performing a vigilance task and in dementia psychopathology as assessed by the Neuropsychiatric Inventory (NPI). A further RCT clinical trial elsewhere (Akhondzadeh et al, 2003) reported that 16 weeks administration of a tincture of $S$. officinalis was efficacious in the amelioration of clinical ratings and the cognitive symptomatology (ADAS-Cog) of AD.

These latter results, taken with the evidence of cognitive performance/mood improvements in healthy cohorts seen in the current and previous studies, suggest that further research might well be directed to the question both of sage's utility in the treatment of disease and natural aging, and the mechanisms underlying any beneficial effects.

\section{ACKNOWLEDGEMENTS}

Materials and a contribution towards the direct costs of the study described herein were provided by MedicHerb, Marlow, Buckinghamshire, UK.

\section{REFERENCES}

Ahearn EP (1997). The use of visual analog scales in mooddisorders: a critical review. J Psychiatr Res 31: 569-579.

Akhondzadeh S, Noroozian N, Mohammadi M, Ohadinia S, Jamshidi AH, Khani M (2003). Salvia officinalis extract in the treatment of patients with mild to moderate Alzheimer's disease: a double blind, randomized and placebo-controlled trial. J Clin Pharmacy Therap 28: 1-7.

Bond A, Lader M (1974). The use of analogue scales in rating subjective feelings. Br J Psychol 47: 211-218.

Ellman GK, Courtney KD, Andres V, Featherstone RM (1961). A new and rapid colorimetric determination of acetylcholinesterase activity. Biochem Pharmacol 7: 88-95.

Giacobini E (2004). Cholinesterase inhibitors: new roles and therapeutic alternatives. Pharmacol Res 50: 433-440.

Grutzlender J, Morris JC (2001). Cholinesterase inhibitors for Alzheimer's disease. Drugs 61: 41-52.

Kennedy DO, Little W, Scholey AB (2004). Attenuation of laboratory induced stress in humans following acute administration of Melissa officinalis (Lemon Balm). Psychosomatic Med 66: 607-613.
Kennedy DO, Scholey AB (2005). Sage and brain function. Nutr Abstracts Rev: Series A 75: 25-31.

Kennedy DO, Scholey AB, Tildesley NTJ, Perry EK, Wesnes KA (2002). Modulation of mood and cognitive performance following acute administration of single doses of Melissa officinalis (Lemon Balm). Pharmacol Biochem Behav 72: 953-964.

Kennedy DO, Wake G, Savelev S, Tildesley NTJ, Perry EK, Wake G et al (2003). Modulation of mood and cognitive performance following administration of single doses of Melissa officinalis (Lemon balm) with human CNS nicotinic and muscarinic receptor binding properties. Neuropsychopharmacology 28: 1871-1881.

Keppel G (1991). Design and Analysis. Prentice Hall: New Jersey. Perry EK, Pickering AT, Wang WW, Houghton PJ, Perry NSL (1999). Medicinal plants and Alzheimer's disease: from ethnobotany to phytotherapy. J Pharmacy Pharmacol 51: 527-534.

Perry N, Court G, Bidet N, Court J, Perry E (1996). European herbs with cholinergic activities: potential in dementia therapy. Int $J$ Geriatric Psychiatr 11: 1063-1069.

Perry NSL, Bollen C, Perry EK, Ballard C (2003). Salvia for dementia therapy: review of pharmacological activity and pilot tolerability clinical trial. Pharmacol, Biochem and Behav 75: 651-659.

Perry NSL, Houghton PJ, Jenner P, Keith A, Perry EK (2002). Salvia lavandulaefolia essential oil inhibits cholinesterase in vivo. Phytomedicine 9: 48-51.

Perry NSL, Houghton PJ, Sampson J, Theobald AE, Har S, LisBalchin $\mathrm{M}$ et al (2001). In vitro activities of S. lavandulaefolia (Spanish Sage) relevant to treatment of Alzheimer's disease. J Pharmacy Pharmacol 53: 1347-1356.

Perry NSL, Houghton PJ, Theobald A, Jenner P, Perry EK (2000). In vitro inhibition of human erythrocyte acetylcholinesterase by Salvia lavandulaefolia essential oil and constituent terpenes. J Pharmacy and Pharmacol 52: 895-902.

Savelev SU, Okello EJ, Perry EK (2004). Butyryl and Acetylcholinesterase inhibitory activities in essential oils of Salvia species and their constituents. Phytother Res 18: 315-324.

Savelev S, Okello E, Perry NSL, Wilkins RM, Perry E (2003). Synergistic and antagonistic interactions of anticholinesterase terpenoids in Salvia lavandulaefolia essential oil. Pharmacol Biochem Behav 75: 661-668.

Speilberger CD, Gorsuch RL, Lushene RE (1969). The State Trait Anxiety Inventory Manual. Consulting Psychologists Press: Palo Alto.

Tildesley NTJ, Kennedy DO, Perry EK, Ballard C, Savelev S, Wesnes KA et al (2003). Salvia lavandulaefolia (Spanish Sage) enhances memory in healthy young volunteers. Pharmacol Biochem Behav 75: 669-674.

Tildesley NTJ, Kennedy DO, Ballard CG, Wesnes KA, Hylands P, Perry EK et al. Sage improves memory and attention in healthy older volunteers: a controlled double blind acute study (submitted).

Tildesley NTJ, Kennedy DO, Perry EK, Ballard C, Wesnes KA, Scholey AB (2005). Cognitive and mood effects of acute administration of Salvia lavandulaefolia (Spanish Sage) to healthy young volunteers. Physiol Behav 83: 699-709.

Wetherell MA, Sidgreaves MC (2005). Secretory immunoglobulin - A reactivity following increases in workload intensity using the Defined Intensity Stress Simulator. Stress Health 21: 99-106.

Wilcock GK, Lilienfeld S, Gaens E (2000). Efficacy and safety of galantamine in patients with mild to moderate Alzheimer's disease: multicentre randomised controlled trial. Galantamine International Study Group. BMJ 321: 1445-1449. 